\title{
Comparison of three evapotranspiration models with eddy covariance measurements for a Populus euphratica Oliv. forest in an arid region of northwestern China
}

\author{
GAO Guanlong, ZHANG Xiaoyou*, YU Tengfei, LIU Bing \\ Cold and Arid Regions Environmental and Engineering Research Institute, Chinese Academy of Sciences, Lanzhou 730000, China
}

\begin{abstract}
The accurate estimation of evapotranspiration (ET) in arid regions is important for improving the water use efficiency of vegetation. Based on successive observations from May to October of 2014, we estimated the ET of a Populus euphratica Oliv. forest during the growing season in an extremely arid region using the PM (Penman-Monteith), SW (Shuttleworth-Wallace) and SSW (an improved canopy transpiration model) models. Estimated ET values were compared with those of the eddy covariance measurements. Results indicated that the actual ET of the P. euphratica forest was always overestimated by the PM model. The accuracy of the SW model was higher than that of the PM model. However, some data were not easily obtained because of the complicated structure of the SW model. The newly proposed SSW model gave the most accurate ET values, and its accuracy was higher at hourly than at daily time scale. In conclusion, the SSW model is more suitable for sparse vegetation system at large scales in extremely arid regions.
\end{abstract}

Keywords: evapotranspiration; Penman-Monteith model; Shuttleworth-Wallace model; SSW model

Citation: GAO Guanlong, ZHANG Xiaoyou, YU Tengfei, LIU Bing. 2016. Comparison of three evapotranspiration models with eddy covariance measurements for a Populus euphratica Oliv. forest in an arid region of northwestern China. Journal of Arid Land, 8(1): 146-156. doi: 10.1007/s40333-015-0017-0

In arid and semi-arid areas, evapotranspiration (ET) is a key component of water cycles and energy balance (Oki and Kanae, 2006; Jung et al., 2010; Villagarcía et al., 2010). Accurate estimation of ET for sparse plant communities is critical for the efficient management of forestry land in arid and semi-arid environments. ET and its components had been measured by various approaches (Gasca-Tucker et al., 2007), including sap flow (Allen and Grime, 1995; Williams et al., 2004; Scott et al., 2006), lysimeter (Zhang et al., 2005), stable isotopes (Evett et al., 1994; Yepez et al., 2003; Williams et al., 2004; Moran et al., 2009) and the eddy covariance (EC) method (Tourula and Heikinheimo, 1998; Zhu et al., 2013, 2014a). Because the measurement of ET is time-consuming and the series data are difficult to be obtained, a mathematical modeling of ET has been developed as a solution (Domingo et al., 1999).

Among the models that had been developed and validated for the ET estimation, the best known are the single-layer Penman-Monteith (PM) model (Monteith and Unsworth, 1990; Rana et al., 1997a,

*Corresponding author: ZHANG Xiaoyou (E-mail: zhangxy@lzb.ac.cn)

Received 2015-03-25 revised 2015-07-29; accepted 2015-08-10

(C) Xinjiang Institute of Ecology and Geography, Chinese Academy of Sciences, Science Press and Springer-Verlag Berlin Heidelberg 2016 
b; Ortega-Farias et al., 2004, 2006) and two-layer Shuttleworth-Wallace (SW) model (Shuttleworth and Wallace, 1985; Wallace et al., 1990; Nichols, 1992; Sene, 1994; Farahani and Ahuja, 1996; Teh et al., 2001). The PM model, which treats the crop canopy as a single uniform cover but neglects evaporation, may be inappropriate for the sparse vegetation canopy (Mo, 1998). However, several studies argued that PM could effectively estimate ET for the sparse vegetation canopy under different soil water conditions (Rana et al., 1997a, b; Ortega-Farias et al., 2004, 2006). The SW model, in which the interactions between fluxes of soil and canopy are taken into account, is suitable for estimating ET for complex or seasonally variable vegetation canopies (Kato et al., 2004; Hu et al., 2009; Zhu et al., 2013). Researchers had mainly focused on improving the accuracy of SW model under specific conditions. Iritz et al. (1999) used a modified SW model to simulate the evaporation of a boreal forest stand. Guan and Wilson (2009) developed a topography- and vegetation-based dual-source ET (TVET) model which used a hybrid of layer and patch approaches in partitioning energy and routing vapor and sensible heat. Hu et al. (2013) combined the SW, Ball-Berry and light-use efficiency models to estimate the ET at forest and grassland sites. However, the complexity and number of parameters were also increased.

It is important to consider both the accuracy and simplicity of the dual-source model. Li et al. (2010) simplified the SW model by introducing the Priestley-Taylor model into the PM equation to estimate soil water evaporation (Monteith, 1965), proposing an improved canopy transpiration (SSW) model, which contrasts with SW in the way in which the two sources interact. The SSW has a simpler structure, which reduces the number of parameters and improves the facilitation of a dual-source model. However, the applicability requires testing in different natural ecosystems.

ET modeling over full canopies is common. However, there has been little research on ET modeling over canopies in a sparse vegetation ecosystem which is in a complex balance between water and energy. Using parameters measured in a Populus euphratica Oliv. forest during the growing season of 2014, we tested whether: (1) the newly proposed SSW model is more accurate than the PM and SW models for the sparse vegetation in extremely arid regions at both hourly and daily time scales; and (2) the PM model is appropriate for the sparsely vegetated canopies.

\section{Materials and methods}

\subsection{Study area}

The study was conducted in the Qidaoqiao P. euphratica forest reserve in Ejin county, Inner Mongolia, China $\left(42^{\circ} 21^{\prime} \mathrm{N}, 101^{\circ} 15^{\prime} \mathrm{E} ; 920.5 \mathrm{~m}\right.$ asl). This region is one of the most arid regions in China. Mean annual evaporation exceeds $3,500 \mathrm{~mm}$ while annual precipitation is $36.6 \mathrm{~mm}, 84 \%$ of which falls in the growing season (Fig. 1). Annual mean air temperature is $8.28^{\circ} \mathrm{C}$, annual mean relative humidity is $35 \%-42 \%$, and moisture index is less than $0.009 \%-0.012 \%$. In the forest reserve, the average tree age is 31 years, with good growth status. The average tree height is $10.2 \mathrm{~m}$, average diameter at breast height is $24.7 \mathrm{~cm}$, and average crown breadth is $442-450 \mathrm{~cm}$. Soil is sandy loam of about 2-m depth and has a volumetric water content of $0.35 \mathrm{~m}^{3} / \mathrm{m}^{3}$. The bulk density of soil is $1.53 \mathrm{~g} / \mathrm{cm}^{3}$.

\subsection{Measurement and data processing}

Uniform open-path EC systems and meteorological instrument were installed at the heights of $20 \mathrm{~m}$ and $10 \mathrm{~m}$ in a tower, respectively, to monitor the $\mathrm{CO}_{2} / \mathrm{H}_{2} \mathrm{O}$ fluxes and environmental conditions at the study site. The tower was located on open spaces in the center of the $P$. euphratica forest and the trees were distributed evenly around the tower. The fetch of eddy covariance measurement is about $300 \mathrm{~m}$ in the predominant upwind direction (Northwest). The EC system consisted of an open-path $\mathrm{CO}_{2} / \mathrm{H}_{2} \mathrm{O}$ gas analyzer (model LI-7500, Li-COR Inc., Lincoln, NE, USA) and a 3D sonic anemometer/thermometer (model CSAT3, Campbell Scientific Inc., Logan, UT, USA). Signals were recorded at $10 \mathrm{~Hz}$ by a datalogger (Model CR3000, Campbell Scientific) and block-averaged at 30-min intervals. Raw CSAT3 and $\mathrm{CO}_{2} / \mathrm{H}_{2} \mathrm{O}$ flux data were processed using EddyPro software 


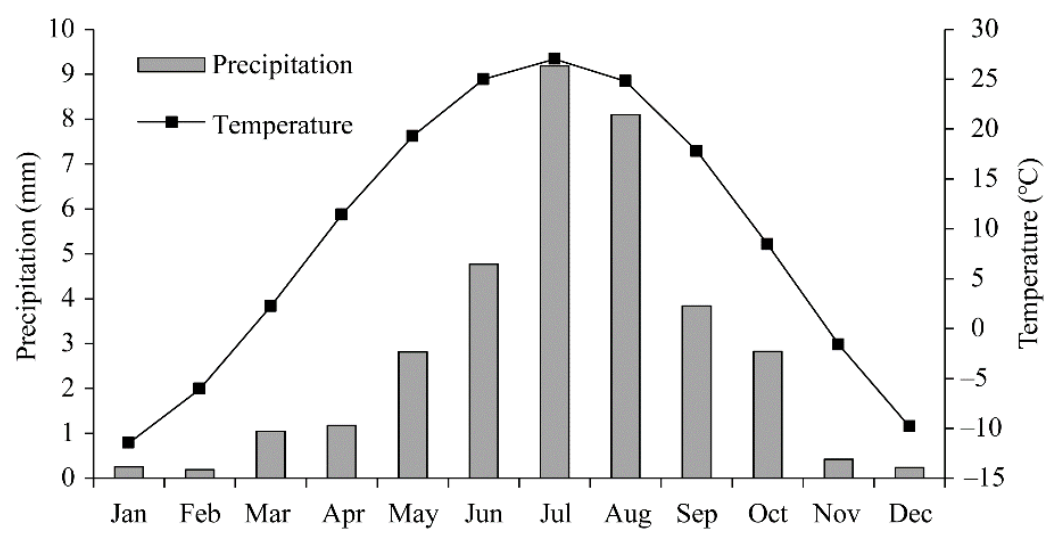

Fig. 1 Monthly precipitation and monthly mean air temperature from 1960 to 2012

(LI-COR Biosciences, Inc., USA), which included the features such as double coordinate rotation, block average detrending, time lag compensation by covariance maximization and density fluctuation compensation by converting to mixing ratio (Burba et al., 2012). Statistical analysis of the series data, including spike count/removal, amplitude resolution, dropouts, absolute limits, skewness and kurtosis, was processed according to Vickers and Mahrt (1997). Quality check flagging was conducted according to the CARBOEUROPE standard (Foken et al., 2004). After detailed postproduction on data, we calculated the ET values at a 0.5 -h average. In order to obtain accurate EC values, we omitted any data collected during rainfall events, instrument malfunction and site inspection days, and during the monthly routine sensor maintenance. Data gaps (no more than a few hours) were filled using linear interpolation. Larger gaps in flux data were replaced by averaged values calculated by the lookup table method (Falge et al., 2001; Zhu et al., 2014b).

Meteorological variables were measured simultaneously with the eddy fluxes and also calculated at 30-min intervals. Net radiation $\left(R_{n}\right)$ was measured at 10 -m height above ground by radiometers (model CNR-4, Kipp \& Zonen, Netherlands). Air temperature $\left(T_{a}\right)$ and relative humidity were also measured at 10-m height above ground (model HMP45C, Campbell Scientific). Barometric pressure was measured by shielded and aspirated probes. Soil temperature was measured using thermocouple probes (109SS, Campbell Scientific) at depths 10, 30, 50, 80 and $150 \mathrm{~cm}$, respectively. Soil heat flux was measured at 5-cm depth by two flux plates (model HFP01SC, Campbell Scientific).

Leaf area index (LAI) was measured once a month using a plant canopy analyzer (LAI2200, LI-COR) with a $10^{\circ}$ view cap from May to October 2014, under diffuse light conditions at dawn or dusk. For each LAI value recorded four readings above the canopy and eight other readings at different points at the base of the canopy were taken.

To make an accurate comparison between ET measurements and PM, SW and SSW estimates, we filtered data from those measurements. First, night-time data with $R_{n}<10 \mathrm{~W} / \mathrm{m}^{2}$ (including dusk and dawn moments) were eliminated because turbulent transport diminished at stable atmospheric conditions during night-time. We also eliminated total ET $(\lambda E)$ values $>800 \mathrm{~W} / \mathrm{m}^{2}$, according to limits proposed by CARBOEUROPE (Villagarcía et al., 2010).

Detailed information on the key environmental variables is essential to assess seasonal variations of actual ET (Zhu et al., 2014a). Changes of daily average $R_{n}, T_{a}$, vapor pressure deficit $(D)$ and wind speed $(u)$ in growing season are shown in Fig. 2. Daily average net radiation was $175.75 \mathrm{~W} / \mathrm{m}^{2}$, varying from 35.80 to $260.77 \mathrm{~W} / \mathrm{m}^{2}$. Daily average air temperature was $21.5^{\circ} \mathrm{C}$, varying from $11.2^{\circ} \mathrm{C}$ (end of September) to $30.6^{\circ} \mathrm{C}$ (mid-July; Fig. 2a). Also, the ecosystem experienced a large daily temperature variation, usually $>15^{\circ} \mathrm{C}$ (data not shown). Daily average wind speed was $3.35 \mathrm{~m} / \mathrm{s}$, varying from 1.76 to $7.04 \mathrm{~m} / \mathrm{s}$. Wind speeds from May to October were much higher than those in other months, mainly due to the prevailing winds in spring and autumn. Daily average vapor pressure deficit was $2.04 \mathrm{kPa}$, ranging from 0.63 to $3.82 \mathrm{kPa}$ during the growing seasons (Fig. 2b). 

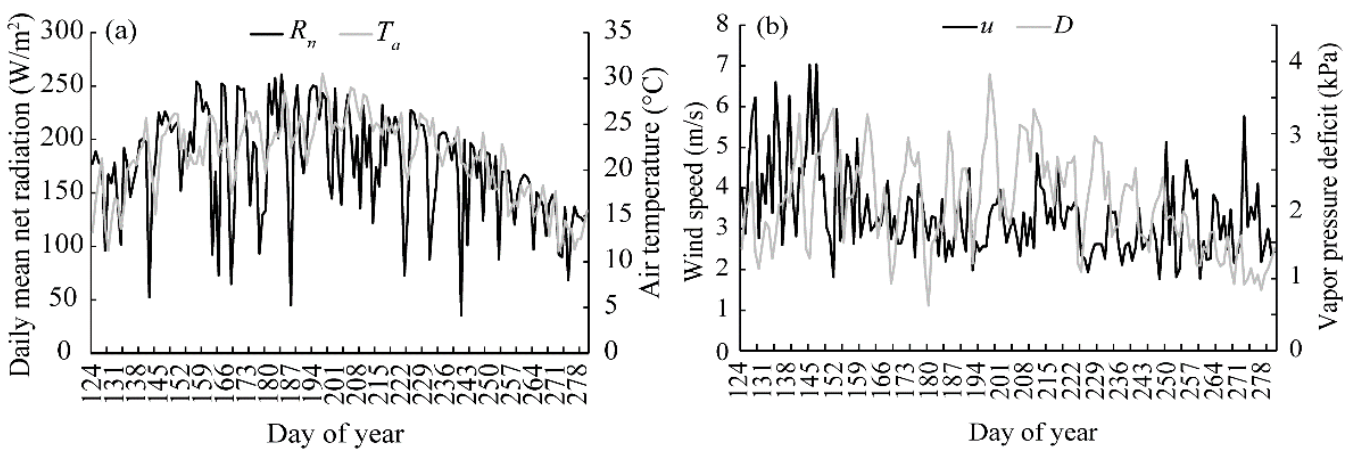

Fig. 2 Seasonal variations of daily mean net radiation $\left(R_{n}\right)$, air temperature $\left(T_{a}\right)$, wind speed $(u)$ and vapor pressure deficit $(D)$

\subsection{Expressions of the models}

The Penman-Monteith (Monteith, 1965) model can be expressed as:

$$
\lambda E T=\frac{\Delta\left(R_{n}-G\right)+\left(\rho C_{p} D / r_{a}\right)}{\Delta+\chi\left(1+\left(r_{c} / r_{a}\right)\right)} .
$$

The SW model estimates latent heat flux from the soil surface and canopy were considered as two distinct sources, and calculated ecosystem evapotranspiration ET as the sum of transpiration $\left(E_{c}\right)$ and soil water evaporation $\left(E_{s}\right)$ :

$\lambda E T=\lambda E_{c}+\lambda E_{s}=C_{c} P M_{c}+C_{s} P M_{s}$

$P M_{c}=\frac{\Delta A_{c}+\left[\rho C_{p} D-\Delta r_{a}^{c} A_{s}\right] /\left(r_{a}^{a}+r_{a}^{c}\right)}{\Delta+\gamma\left[1+\frac{r_{s}^{c}}{r_{a}^{a}+r_{a}^{c}}\right]}$,

$$
P M_{s=} \frac{\Delta A_{c}+\left[\rho C_{p} D-\Delta r_{a}^{s}\left(A_{c}-A_{s}\right)\right] /\left(r_{a}^{a}+r_{a}^{s}\right)}{\Delta+\gamma\left[1+\frac{r_{s}^{s}}{r_{a}^{a}+r_{a}^{s}}\right]},
$$

$A_{s}=R_{n s}-G$,

$$
A_{c}=R_{n}-G,
$$

$C_{c}=\frac{R_{s}\left(R_{c}+R_{a}\right)}{R_{s} R_{c}+R_{c} R_{a}+R_{s} R_{a}}=\frac{1}{1+\frac{R_{c} R_{a}}{R_{s}\left(R_{c}+R_{a}\right)}}$,

$R_{c}=(\Delta+\gamma) r_{a}^{c}+\gamma r_{s}^{c}$,

$R_{s}=(\Delta+\gamma) r_{a}^{s}+\gamma r_{s}^{s}$.

The simpler structure of the SSW model with its fewer parameters can estimate the $E_{c}$ and $E_{S}$, respectively, and only requires simple meteorological data. The equations are:

$$
\begin{gathered}
\mathrm{E}_{\mathrm{s}}=\alpha_{\mathrm{E}} \tau \frac{\Delta}{\lambda(\Delta+\gamma)}\left(\mathrm{R}_{\mathrm{n}}-\mathrm{G}\right)\left\{\begin{array}{c}
\tau \ll \tau_{\mathrm{c}}, \alpha_{\mathrm{E}}=1 \\
\tau>\tau_{\mathrm{c}}, \alpha_{\mathrm{E}}=\alpha-(\alpha-1)(1-\tau)\left(1-\tau_{\mathrm{c}}\right),
\end{array}\right. \\
E_{c}=\frac{1 \Delta R_{n c}+\left(\rho C_{p} D / r_{a}^{c}\right)+\Delta\left(1-\alpha_{E} \tau\right)\left(R_{n}-G\right)\left(r_{a}^{a} / r_{a}^{c}\right)}{\lambda} .
\end{gathered}
$$

\subsection{Determination of parameters}

Parameters of the PM, SW and SSW models can be calculated according to:

$r_{a}=\frac{\ln ((z-d) /(h-d)) \ln \left((z-d) / z_{0}\right)}{u k^{2}}$,

$r^{*}=\frac{\Delta+\gamma}{\Delta} \frac{\rho C_{p} D}{\gamma\left(R_{n}-G\right)}$,

$R_{n c}=R_{n}(1-\exp (-k L A I))$,

$r_{s}^{s}=c \theta^{e}$

$$
\begin{gathered}
r_{c}=r_{a}\left(a \frac{r^{*}}{r_{a}}+b\right), \\
R_{n s}=R_{n} \exp (-k L A I), \\
\Delta=\frac{4098\left[0.6108 \exp \left(\frac{17.27 T_{a}}{T_{a}+237.3}\right)\right]}{\left(T_{a}+237.3\right)^{2}}, \quad(21)
\end{gathered}
$$




$$
\begin{aligned}
& r_{b}=\frac{100}{n} \frac{\sqrt{w / u_{h}}}{1-\exp (-n / 2)}, \\
& n=\left\{\begin{array}{l}
2.5, \quad h_{c} \ll 1 \\
2.306+0.194 h_{c}, 1<h_{c}<10, \\
4.25, h_{c} \gg 10
\end{array}\right. \\
& r_{a}^{a}=\frac{L A I}{4} r_{a}^{a}(\alpha)+\frac{(4-L A I)}{4} r_{a}^{a}(0) \text {, } \\
& r_{a}^{s}(0)=\frac{\ln \left(\frac{z}{z_{0}^{\prime}}\right) \ln \left\{\frac{\left(d+z_{0}\right)}{z_{0}^{\prime}}\right\}}{u k^{2}} \text {, } \\
& r_{a}^{s}(\alpha)=\frac{\ln \left(\frac{z-d}{z_{0}}\right)}{u k^{2}} \frac{h}{n(h-d)} \times\left[\exp n-\exp \left[n\left\{1-\frac{\left(d+z_{0}\right)}{h}\right\}\right]\right] \text {, } \\
& r_{a}^{s}=\frac{L A I}{4} r_{a}^{s}(\alpha)+\frac{(4-L A I)}{4} r_{a}^{s}(0) \text {, } \\
& r_{a}^{a}(0)=\frac{\ln \left(\frac{z}{z_{0}^{\prime}}\right) \ln \left(\frac{z}{z_{0}^{\prime}}\right)}{u k^{2}}-r_{a}^{s}(0) \text {, } \\
& r_{a}^{a}(\alpha)=\frac{\ln \left(\frac{z-d}{z_{0}}\right)}{u k^{2}}\left[\ln \left\{\frac{(z-d)}{h-d}\right\}+\frac{h}{n(h-d)} \times\left[\exp \left[n\left\{1-\frac{\left(d+z_{0}\right)}{h}\right\}\right]-1\right]\right], \\
& d=1.1 h \ln \left(1+\left(C_{d} L A I\right)^{0.25}\right) \text {, } \\
& z_{0}^{\prime}=0.01 h \text {, } \\
& \text { (32) } \\
& z_{0}=z_{0}^{\prime}+0.3 h\left(C_{d} L A I\right)^{0.5}, \\
& u=u_{z} \frac{4.87}{\ln (67.8 z-5.42)} \text {, } \\
& u_{h}=\frac{\ln \left[(h-d) / z_{0}\right]}{\ln \left[(z-d) / z_{0}\right]} u,
\end{aligned}
$$

Where, ET, total evapotranspiration (mm); $E_{c}$, canopy transpiration $(\mathrm{mm}) ; E_{s}$, soil evaporation $(\mathrm{mm})$; $C_{i}$, resistance coefficient of $i$ source ( $c$ and $\left.s\right) ; P M_{i}$, Penman-Monteith equations for each $i$ source $(c$ and $\left.s ; \mathrm{W} / \mathrm{m}^{2}\right) ; R_{n}$, net radiation $\left(\mathrm{W} / \mathrm{m}^{2}\right) ; R_{n i}$, net radiation for each $i$ source $\left(c\right.$ and $\left.s ; \mathrm{W} / \mathrm{m}^{2}\right)$; $G$, soil heat flux $\left(\mathrm{W} / \mathrm{m}^{2}\right) ; r_{a}$, aerodynamic resistance (s/m; Perrier, 1975a, b); $r_{c}$, surface canopy resistance (s/m; Katerji and Perrier 1983); $r^{*}$, critical resistance $\left(\mathrm{s} / \mathrm{m}\right.$; Pereira et al., 1999); $r_{a}^{a}$, aerodynamic resistance between the canopy source height and reference level $(\mathrm{s} / \mathrm{m}$; Shuttleworth and Wallace, 1985); $r_{a}^{s}$, aerodynamic resistance between the soil and canopy source height $(\mathrm{s} / \mathrm{m}$; Shuttleworth and Wallace, 1985); $r_{a}^{c}$, bulk boundary layer resistance of the vegetative elements in the canopy (s/m; Shuttleworth and Wallace, 1985; Brisson et al., 1998); $r_{s}^{c}$, canopy resistance (s/m; Iritz et al., 1999); $r_{s}^{s}$, soil surface resistance (s/m; Dolman, 1993); $\rho$, air density $\left(1.293 \mathrm{Kg} / \mathrm{m}^{3}\right.$; Ács, 2003); $C_{p}$, specific heat at constant pressure (1,012 J/(kg.K); Ács, 2003); $D$, vapor pressure deficit in the air $(\mathrm{kPa}) ; \Delta$, slope of the saturated vapor pressure versus temperature curve $(\mathrm{kPa} / \mathrm{K}$; Allen et al., $1998) ; \gamma$, psychometric constant $\left(0.067 \mathrm{kPa} / \mathrm{K}\right.$; Ács, 2003); $\alpha_{E}$, Priestley-Taylor coefficient (Tanner and Jury, 1976); $\tau_{c}$, constant value at which the $L A I$ is sufficient for $\alpha_{E}$ to reach unity (Tanner and Jury, 1976); $L A I$, leaf area index $\left(\mathrm{m}^{2} / \mathrm{m}^{2}\right) ; L A I_{s}$, leaf area index for which these parameters were determined $\left(9 \mathrm{~m}^{2} / \mathrm{m}^{2}\right.$; Lohammar et al., 1980); $\theta$, actual soil moisture content in the surface layer $\left(\mathrm{m}^{3} / \mathrm{m}^{3}\right) ; z$, reference height above the forest at which meteorological measurements are available $(\mathrm{m}) ; z_{0}$, roughness length of a forest with complete canopy cover ( $L A I=4 ; \mathrm{s} / \mathrm{m}$; Lund and Soegaard, 2003); $z_{0}^{\prime}$, roughness length of bare soil (m; Yu and Sun, 2006); $h$, canopy height (10.2 m); $d$, zero plane displacement height (m; Lund and Soegaard, 2003); $C_{d}$, drag coefficient of the leaves (0.07; Shuttleworth and Gurney, 1990); $k$, extinction coefficient of light attenuation (0.5; Campbell and Norman, 1989); $u$, mean wind speed at the reference height (m/s; Guan and Wilson, 2009); $r_{b}$, leaf boundary layer resistance (s/m; Shuttleworth and Gurney, 1990); $w$, representative leaf width $(\mathrm{m}) ; u_{h}$, mean wind speed at the canopy (m/s; Guan and Wilson, 2009); $u_{z}$, wind speed at $z-\mathrm{m}$ height above ground $(\mathrm{m} / \mathrm{s}) ; \sigma_{b}$, shielding factor (0.5; Shuttleworth and Wallace, 1985; Brisson et al., 1998); $a$, empirical calibration coefficient (0.55; Shi et al., 2008); $b$, empirical calibration coefficient (1.31; Shi et al., 2008); $c$, empirical constant (3.5 s/m; Dolman, 1993); e, empirical constant (2.3; Dolman, 1993); $f$, empirical constant (24.5 s/m; Cienciala et al., 1994); $g$, empirical constant (0.5 kPa; Cienciala et al., 1994); $i$, empirical constant $\left(547 \mathrm{~W} / \mathrm{m}^{2}\right.$; Cienciala et al., 1994); $n$, eddy diffusivity decay constant (4.25; Zhou et al., 2006).

\subsection{Assessments}

Model goodness-of-fit was evaluated by comparing ET predicted by the PM, SW and SSW models 
with EC measurements. If the models perfectly predicted the data, all observed-versus-predicted points would lie exactly on the line $x=y$. We also used the following equations of root mean square error (RMSE), relative error (RE) and mean absolute error (MAE) to characterize the deviation of the calculated values from the observed:

$$
\begin{array}{r}
R M S E=\sqrt{\frac{\sum\left(O_{i}-M_{i}\right)^{2}}{N}}, \quad \text { (36) } \quad R E=\frac{\sum\left(\left|O_{i}-M_{i}\right| / O_{i}\right)}{N}, \\
M A E=\frac{\sum\left(\left|O_{i}-M_{i}\right|\right)}{N}
\end{array}
$$

Where $O_{i}$ and $M_{i}$ are the observed and modeled values, respectively, and $N$ is the total number of measurements.

Analysis of model sensitivity to a parameter is essential for quantifying the model uncertainty (Long et al., 2011). A simple method proposed by Zhan et al. (1996) was used to analyze this sensitivity:

$$
S_{p}=\left|\frac{E T_{-}-E T_{+}}{E T_{0}}\right| \text {. }
$$

Where $E T_{0}, E T_{-}$and $E T_{+}$are ETs derived by the model when the corresponding parameter equals to its reference value, i.e. $P_{0}, 1.1 P_{0}$ and $0.9 P_{0}$, respectively. Results of the sensitivity analysis for the SSW model showed that parameters $L A I\left(S_{p}=0.230\right)$ and $R_{n}\left(S_{p}=0.228\right)$ had greater sensitivities, while, parameters $D\left(S_{p}=0.019\right)$ and $u\left(S_{p}=0.001\right)$ had lower sensitivities.

\section{Results}

\subsection{The characteristic of ET}

Hourly and daily values of ET estimated from the PM, SW and SSW models and measured by the EC method were shown in Figs. 3 and 4. Hourly trends of ET during the ten days were similar. Hourly values of ET increased rapidly from 9:00 and reached the maximum at 14:00. Afterward, it decreased rapidly until sunset (Fig. 3). Daily values of ET were lowest at the seventh day and this was mainly due to the cloudy weather condition. The average of daily ET was $3.822 \mathrm{~mm} / \mathrm{d}$, ranging from 0.983 to $6.709 \mathrm{~mm} / \mathrm{d}$. ET value in July $(5.287 \mathrm{~mm} / \mathrm{d})$ was greater than those of other months $(3.464 \mathrm{~mm} / \mathrm{d})$ of the growing season (Fig. 4). Total ETs from May to September were 70.902, 124.138, 163.901, 132.653 and $96.092 \mathrm{~mm}$, respectively. Total ET value of the $P$. euphratica forest during the growing season was $587.686 \mathrm{~mm}$.

\subsection{Performance of the three models}

\subsubsection{Comparison of estimated and measured hourly ET}

Figure 3 and Table 1 show comparison and correlation between estimated hourly ET by the PM, SW and SSW models and measured hourly ET by the EC method during the growing season of 2014 . Diurnal evolution of ET was similar between the EC method and the three models. Generally, during the morning (before 9:00) and afternoon (after 17:00), there were no significant differences between estimated ET by the SW and SSW models and measured ET by the EC; the estimates by the PM model were slightly smaller than those measurements. During the period of 11:00 to 17:00, the maximum estimates by the PM were a little higher than those of the EC, whereas the estimates by the SW and SSW were closer to the EC values (Fig. 3).

The slope of regression equation between the estimates by the PM model and measured ET by the EC method for the entire growing period was 1.974, and the RMSE, RE and MAE were 0.277, 0.043 and 0.204, respectively. This indicates that the ET values by the PM model were overestimated.

The regression equation slopes of the SW and SSW models were 0.783 and 0.788 , with RMSE, RE and MAE values of $0.103,-0.004$ and 0.069 , and $0.082,0.015$ and 0.061 , respectively (Table 1 ). This reveals that no significant deviation between the two models was observed. Accuracy of the SSW model was higher than that of SW, but the accuracy of these two models was higher than that of the PM model. 


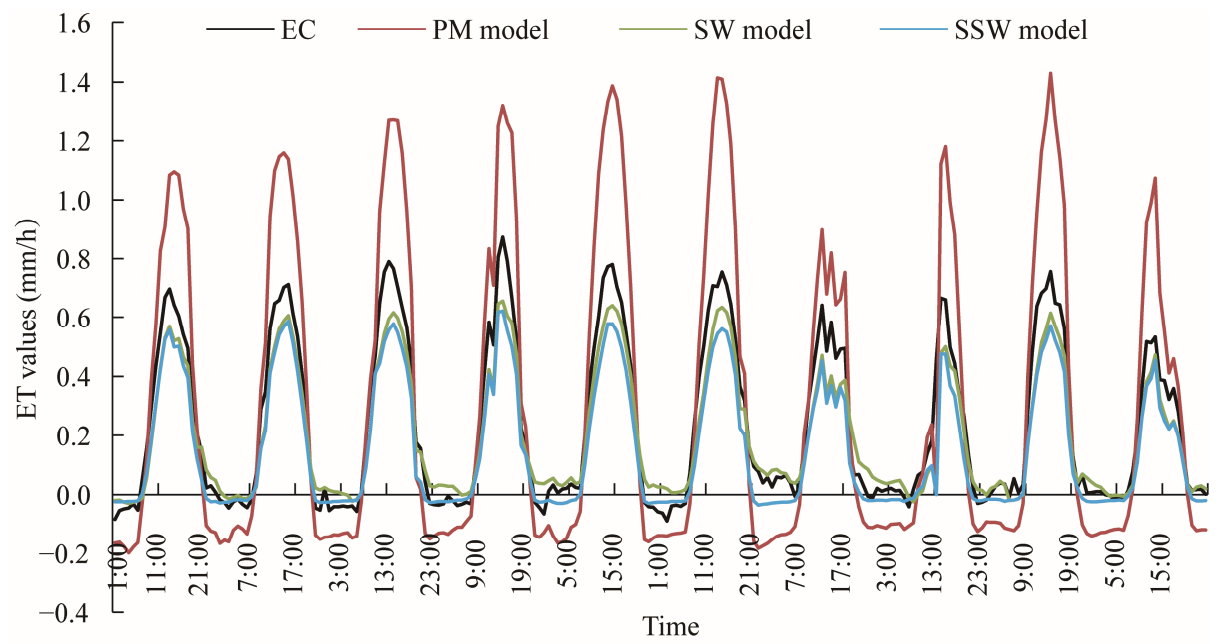

Fig. 3 Hourly patterns of estimated ET from PM, SW and SSW models and measured ET by EC method during the growing season of 2014. The data set contains consecutive measures of ten days.

Table 1 Comparison between estimated hourly ET by the three models and measured ET by the EC method during the growing season of 2014

\begin{tabular}{llllll}
\hline Model & Regression equation & RMSE & RE & MAE & $R^{2}$ \\
\hline PM & $y=1.9743 x-0.0728$ & 0.277 & 0.043 & 0.204 & 0.861 \\
SW & $y=0.7833 x+0.0429$ & 0.103 & -0.004 & 0.069 & 0.765 \\
SSW & $y=0.7878 x-0.0026$ & 0.082 & 0.015 & 0.061 & 0.891 \\
\hline
\end{tabular}

\subsubsection{Comparison of estimated and measured daily ET}

The relationship between estimated daily ET and EC-measured values was shown in Fig. 4 and Table 2. Estimates from the SSW model were similar to the EC values, whereas the PM model overestimated them significantly.

Regression equation slope of the SSW model was 0.549, with RMSE, RE and MAE values of $1.210,0.286$ and 1.049 , respectively (Table 2). The accuracy of SSW was still the highest at daily time scale, but it was lower than that at hourly time scale (slope of the regression equation of SSW was 0.788 , with RMSE, RE and MAE values of 0.082, 0.015 and 0.061 , respectively).

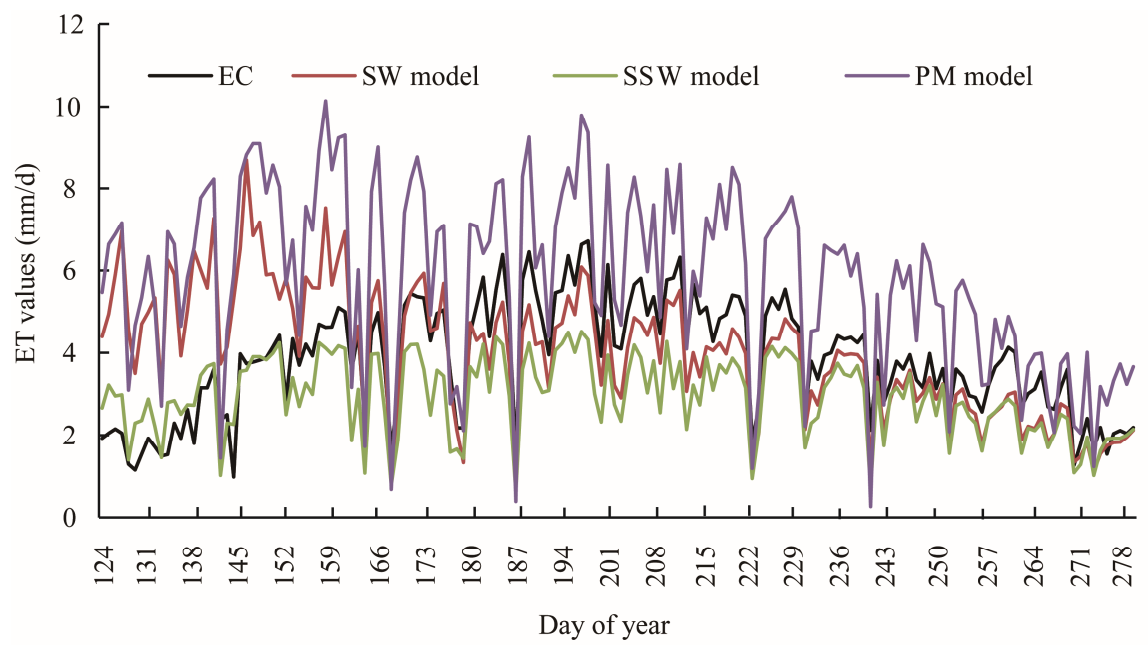

Fig. 4 Daily patterns of estimated ET from PM, SW and SSW models and measured ET by EC method during the growing season of 2014. The data set contains sums of hourly measurements. 
Table 2 Comparison between the estimated daily values of ET by the three models and measured ET by the EC method during the growing season of 2014

\begin{tabular}{llllll}
\hline Model & Regression equation & RMSE & RE & MAE & $R^{2}$ \\
\hline PM & $y=1.1304 x+1.4781$ & 2.526 & 0.664 & 2.098 & 0.497 \\
SW & $y=0.5032 x+2.0935$ & 1.543 & 0.405 & 1.113 & 0.204 \\
SSW & $y=0.5493 x+0.8430$ & 1.210 & 0.286 & 1.049 & 0.652 \\
\hline
\end{tabular}

\subsection{Relationship between monthly Ec/ET obtained by the SSW model and LAI}

We analyzed the monthly Ec and ET obtained by the SSW model and the relationship between Ec/ET and LAI during the growing season of 2014 (Fig. 5). Total estimated Ecs and ETs from May to September were 43.36, 50.30, 61.57, 62.96 and $56.00 \mathrm{~mm}$, and 81.39, 91.90, 108.77, 95.90 and 86.95 $\mathrm{mm}$, respectively. The variation tendency between Ec/ET and LAI was similar. The ratio of Ec/ET increased from 0.533 to 0.657 from May to August, and then decreased from 0.657 to 0.644 from August to September. Similarly, LAI increased from 1.850 to 2.267 from May to August, and decreased from 2.267 to 2.208 from August to September.

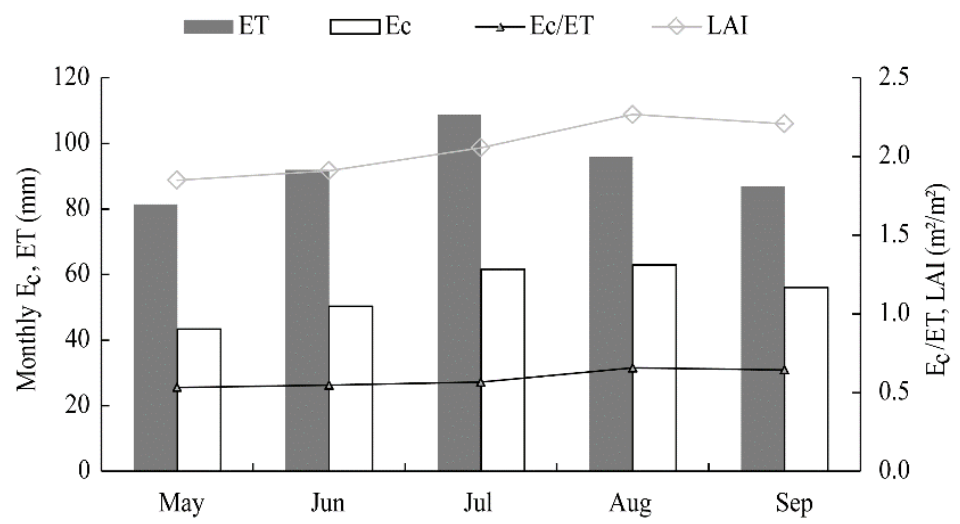

Fig. 5 Patterns of monthly Ec and ET obtained from the SSW model and relationship between Ec/ET and LAI

\section{Discussion}

In the last decades, there are many studies on the comparison of the PM and SW models. Zhang et al. (2008) simulated ET in the arid desert region of northwest China and compared the estimated ET with those of the Bowen ratio-energy balance method. Results indicated that the SW model can simulate ET well, while the PM model significantly overestimated. Fisher et al. (2005) compared the potential ET of five ET models in Ponderosa pine forest ecosystem and found that the accuracy of the SW model was higher than that of the PM model. Gharsallah et al. (2013) estimated the ET of six ET models in an irrigated maize agro-ecosystem of northern Italy, and found that the PM model combined with the Penman-Monteith model and the SW model can achieve good performances.

In our study, the PM model significantly overestimated ET at both hourly and daily time scales. Similar conclusions were drawn by Ortega-Farias et al. (2006) and Zhang et al. (2008). They both found that PM overestimated the measured ET at 20- and 30-min intervals. Possible reasons for this overestimation are as follows: (1) the extremely dry soil surface sharply increased surface resistance and prevented soil water from evaporation. Although the total ET slightly increased with the intense solar radiation and greater vapor pressure deficit, it was less than that determined by the meteorological variables because the resistance of surface canopy and soil conditions in the model cannot be accurately included; (2) vegetation coverage of the $P$. euphratica forest is very low, and therefore it did not satisfy the assumptions of the PM model. However, Li et al. (2010) obtained an opposite conclusion, that the PM model underestimated the ET. Such a discrepancy may result from the canopy resistance and soil water status (Zhang et al., 2008). In the experiment of Li et al. (2010), 
full irrigation management was applied, resulting in higher soil water content and lower soil surface resistance. In our experiment, the soil was extremely dry and soil surface resistance was generally higher than canopy resistance, which resulted in this discrepancy. Results also showed there were no significant deviations between the SW and SSW models after day 155; however, estimates obtained from both models were much higher than those estimated from the SSW model and the EC measurements before day 155 . This was mainly due to the high values of vapor pressure (Fig. 2). Generally, the accuracy of the SSW model was slightly higher than that of SW model and the accuracies of both models were higher than the PM model, especially at the hourly time scale. Li et al. (2010) obtained a similar conclusion that there was a small difference between the SW and SSW models but the accuracies of the two models were both superior to that of the PM model.

Although the SSW model agreed well with the measurements at both hourly and daily time scales, it did not consider the evaporation from canopy. Tourula and Heikinheimo (1998) found that canopy interception accounted for $9 \%-14 \%$ of total ET in a barley crop (LAI, 3.5-4.5 $\mathrm{m}^{2} / \mathrm{m}^{2}$ ). Although LAI $\left(1.9-2.3 \mathrm{~m}^{2} / \mathrm{m}^{2}\right)$ in $P$. euphratica forest was lower and its canopies were not as dense as the barley crop, canopy interception may account for a significant amount of the total ET. Moreover, some types of herbs (such as Sophora alopecuroides L.) grew under the canopy of $P$. euphratica at our experimental site, which may increase the actual ET. More work is needed to find the role of interception in the estimation of ET and to improve the accuracy of ET models in extremely arid regions with sparse vegetation.

\section{Conclusions}

We estimated the ET of a $P$. euphratica forest reserve using the PM, SW and SSW models. The results were compared with that of the EC method at both hourly and daily time scales. The conclusions are: (1) the SSW model appears more applicable than PM and SW models for sparse vegetation in extremely arid regions at both hourly and daily time scales; and (2) the PM model is not appropriate for sparse vegetation canopy.

\section{Acknowledgements}

This work was supported by the National Natural Science Foundation of China (41271037) and the Youth Foundation of National Natural Science of China (41401033). We gratefully acknowledge the anonymous reviewers for their valuable comments on an earlier version of our manuscript.

\section{References}

Ács F. 2003. A comparative analysis of transpiration and bare soil evaporation. Boundary-Layer Meteorology, 109: 139-162.

Allen R G, Pereira L S, Raes D, et al. 1998. Crop evapotranspiration-guidelines for computing crop water requirements. In: FAO Irrigation and Drainage Paper, No. 56. Rome: FAO.

Allen S J, Grime V L. 1995. Measurements of transpiration from savannah shrubs using sap flow gauges. Agricultural and Forest Meteorology, 75(1-3): 23-41.

Brisson N, Itier B, L'Hotel J C, et al. 1998. Parameterisation of the Shuttleworth-Wallace model to estimate daily maximum transpiration for use in crop models. Ecological Modelling, 107(2-3): 159-169.

Burba G, Schmidt A, Scott RL, et al. 2012. Calculating $\mathrm{CO}_{2}$ and $\mathrm{H}_{2} \mathrm{O}$ eddy covariance fluxes from an enclosed gas analyzer using an instantaneous mixing ratio. Global Change Biology, 18(1): 385-399.

Campbell G S, Norman J M. 1989. The description and measurement of plant canopy structure. In: Russell G, Marshall B, Jarvis P G. Plant Canopies: Their Growth Form, and Function. Cambridge: Cambridge University Press, 1-19.

Cienciala E, Eckersten H, Lindroth A, et al. 1994. Simulated and measured water uptake by Picea abies under non-limiting soil water conditions. Agricultural and Forest Meteorology, 71(1-2): 147-164.

Dolman A J. 1993. A multiple-source land surface energy balance model for use in general circulation models. Agricultural and Forest Meteorology, 65(1-2): 21-45.

Domingo F, Villagarcía L, Brenner A J, et al. 1999. Evapotranspiration model for semi-arid shrub-lands tested against data from SE Spain. Agricultural and Forest Meteorology, 95(2): 67-84.

Evett S R, Matthias A D, Warrick A W. 1994. Energy balance model of spatially variable evaporation from bare soil. Soil Science 
Society of America Journal, 58(6): 1604-1611.

Falge E, Baldocchi D, Olson R, et al. 2001. Gap filling strategies for defensible annual sums of net ecosystem exchange. Agricultural and Forest Meteorology, 107(1): 43-69.

Farahani H J, Ahuja L R. 1996. Evapotranspiration modeling of partial canopy/residue-covered fields. Transaction of the American Society of Agricultural and Biological Engineers, 39(6): 2051-2064.

Fisher J B, DeBiase T A, Qi Y, et al. 2005. Evapotranspiration models compared on a Sierra Nevada forest ecosystem. Environmental Modelling and Software, 20(6): 783-796.

Foken T, Göockede M, Mauder M, et al. 2004. Post-field data quality control. In: Lee X H, Massman W, Law B. Handbook of Micrometeorology: A Guide for Surface Flux Measurement and Analysis. New York: Kluwer Academic Publishers, 181-208.

Gasca-Tucker D L, Acreman M C, Agnew C T, et al. 2007. Estimating evaporation from a wet grassland. Hydrology and Earth System Sciences, 11(1): 270-282.

Gharsallah O, Facchi A, Gandolfi C. 2013. Comparison of six evapotranspiration models for a surface irrigated maize agro-ecosystem in Northern Italy. Agricultural Water Management, 130: 119-130.

Guan H D, Wilson J L. 2009. A hybrid dual-source model for potential evaporation and transpiration partitioning. Journal of Hydrology, 377(3-4): 405-416.

Hu Z M, Yu G R, Zhou Y L, et al. 2009. Partitioning of evapotranspiration and its controls in four grassland ecosystems: application of a two-source model. Agricultural and Forest Meteorology, 149(9): 1410-1420.

Hu Z M, Li S G, Yu G R, et al. 2013. Modeling evapotranspiration by combing a two-source model, a leaf stomatal model, and a light-use efficiency model. Journal of Hydrology, 501: 186-192.

Iritz Z, Lindroth A, Heikinheimo M, et al. 1999. Test of a modified Shuttleworth-Wallace estimate of boreal forest evaporation. Agricultural and Forest Meteorology, 98-99: 605-619.

Jung M, Reichstein M, Ciais P, et al. 2010. Recent decline in the global land evapotranspiration trend due to limited moisture supply. Nature, 467(7318): 951-954.

Katerji N, Perrier A. 1983. A model of actual evapotranspiration (ETR) for a field of lucerne: the role of a crop coefficient. Agronomie, 3(6): 513-521.

Kato T, Kimura R, Kamichika M. 2004. Estimation of evapotranspiration, transpiration ratio and water-use efficiency from a sparse canopy using a compartment model. Agricultural Water Management, 65(3): 173-191.

Li X Y, Yang P L, Ren S M, et al. 2010. Modeling cherry orchard evapotranspiration based on an improved dual-source model. Agricultural Water Management, 98(1): 12-18.

Lohammar T, Larsson S, Linder S, et al. 1980. FAST: simulation models of gaseous exchange in Scots pine. In: Persson T. Structure and Function of Northern Coniferous Forests: An Ecosystem Study. Stockholm: Swedish Natural Science Council, 32 : $505-523$

Long D, Singh V P, Li Z L. 2011. How sensitive is SEBAL to changes in input variables, domain size and satellite sensor? Journal of Geophysical Research, 116(D21): D21107.

Lund M R, Soegaard H. 2003. Modelling of evaporation in a sparse millet crop using a two-source model including sensible heat advection within the canopy. Journal of Hydrology, 280(1-4): 124-144.

Mo X G. 1998. Modeling and validating water and energy transfer in soil-vegetation-atmosphere system. Acta Meteorological Sinica, 56(3): 323-332. (in Chinese)

Monteith J L. 1965. Evaporation and environment. The state and movement of water in living organisms. Symposia of the Society for Experimental Biology. England: Cambridge University Press, 19: 205-234.

Monteith J L, Unsworth M. 1990. Principles of Environmental Physics ( $2^{\text {nd }}$ ed.). London: Butterworth-Heinemann, 286.

Moran M S, Scott R L, Keefer T O, et al. 2009. Partitioning evapotranspiration in semiarid grassland and shrubland ecosystems using time series of soil surface temperature. Agricultural and Forest Meteorology, 149(1): 59-72.

Nichols W D. 1992. Energy budgets and resistances to energy transport in sparsely vegetated rangeland. Agricultural and Forest Meteorology, 60(3-4): 221-247.

Oki T, Kanae S. 2006. Global hydrological cycles and world water resources. Science, 313(5790): 1068-1072.

Ortega-Farias S, Olioso A, Antonioletti R, et al. 2004. Evaluation of the Penman-Monteith model for estimating soybean evapotranspiration. Irrigation Science, 23(1): 1-9.

Ortega-Farias S, Olioso A, Fuentes S, et al. 2006. Latent heat flux over a furrow-irrigated tomato crop using Penman-Monteith equation with a variable surface canopy resistance. Agricultural Water Management, 82(3): 421-432.

Pereira L S, Perrier A, Allen R G, et al. 1999. Evapotranspiration: concepts and future trends. Journal of Irrigation and Drainage Engineering-ASCE, 125(2): 45-51.

Perrier A. 1975a. Physical study of evapotranspiration in natural conditions. I. Evaporation and summary of natural surface energy. 
Annales Agronomiques, 26: 1-18. (in French)

Perrier A. 1975b. Physical study of evapotranspiration in natural conditions. III. Actural and potential evapotranspiration of canopies. Annales Agronomiques, 26: 229-243. (in French)

Rana G, Katerji N, Mastrorilli M, et al. 1997a. A model for predicting actual evapotranspiration under soil water stress in a Mediterranean region. Theoretical and applied Climatology, 56(1-2): 45-55.

Rana G, Katerji N, Mastrorilli M, et al. 1997b. Validation of a model of actual evapotranspiration for water stressed soybeans. Agricultural and Forest Meteorology, 86(3-4): 215-224.

Scott R L, Huxman T E, Cable W L, et al. 2006. Partitioning of evapotranspiration and its relation to carbon dioxide exchange in a Chihuahuan Desert shrubland. Hydrological Processes, 20(15): 3227-3243.

Sene K J. 1994. Parameterisations for energy transfers from a sparse vine crop. Agricultural and Forest Meteorology, 71(1-2): 118.

Shi T T, Guan D X, Wang A Z, et al. 2008. Comparison of three models to estimate evapotranspiration for a temperate mixed forest. Hydrological Processes, 22(17): 3431-3443.

Shuttleworth W J, Wallace J S. 1985. Evaporation from sparse crops-an energy combination theory. Quarterly Journal of the Royal Meteorological Society, 111(469): 839-855.

Shuttleworth W J, Gurney R J. 1990. The theoretical relationship between foliage temperature and canopy resistance in sparse crops. Quarterly Journal of the Royal Meteorological Society, 116(492): 497-519.

Tanner C B, Jury W A. 1976. Estimating evaporation and transpiration from a row crop during incomplete cover. Agronomy Journal, 68(2): 209-243.

Teh C B S, Simmonds L P, Wheeler T R. 2001. Modelling the partitioning of solar radiation capture and evapotranspiration in intercropping systems. In: Proceedings of the $2^{\text {nd }}$ International Conference on Tropical Climatology, Meteorology and Hydrology. TCMH-2001, Brussels, Belgium: TCMH.

Tourula T, Heikinheimo M. 1998. Modelling evapotranspiration from a barley field over the growing season. Agricultural and Forest Meteorology, 91(3-4): 237-250.

Vickers D, Mahrt L. 1997. Quality control and flux sampling problems for tower and aircraft data. Journal of Atmospheric and Oceanic Technology, 14(3): 512-526.

Villagarcía L, Were A, García M, et al. 2010. Sensitivity of a clumped model of evapotranspiration to surface resistance parameterisations: Application in a semi-arid environment. Agricultural and Forest Meteorology, 150(7-8): 1065-1078.

Wallace J S, Roberts J M, Sivakumar M V K. 1990. The estimation of transpiration from sparse dryland millet using stomatal conductance and vegetation area indices. Agricultural and Forest Meteorology, 51(1): 35-49.

Williams D G, Cable W, Hultine K, et al. 2004. Evapotranspiration components determined by stable isotope, sap flow and eddy covariance techniques. Agricultural and Forest Meteorology, 125(3-4): 241-258.

Yepez E A, Williams D G, Scott R L, et al. 2003. Partitioning overstory and understory evapotranspiration in a semiarid savanna woodland from the isotopic composition of water vapor. Agricultural and Forest Meteorology, 119(1-2): 53-68.

Yu G R, Sun X M. 2006. Principles of Flux Measurement in Terrestrial Ecosystems. Beijing: Higher Education Press, 137-142. (in Chinese)

Zhan X, Kustas W P, Humes K S. 1996. An inter-comparison study on models of sensible heat flux over partial canopy surfaces with remotely sensed surface temperature. Remote Sensing of Environment, 58(3): 242-256.

Zhang B Z, Kang S Z, Li F S, et al. 2008. Comparison of three evapotranspiration models to Bowen ration-energy balance method for a vineyard in an arid desert region of northwest China. Agricultural and Forest Meteorology, 148(10): 1629-1640.

Zhang Y S, Munkhtsetseg E, Kadota T, et al. 2005. An observational study of ecohydrology of a sparse grassland at the edge of the Eurasian Cryosphere in Mongolia. Journal of Geophysical Research: Atmospheres, 110(D14), doi: 10.1029/2004jd005474.

Zhou M C, Ishidaira H, Hapuarachchi H P, et al. 2006. Estimating potential evapotranspiration using Shuttleworth-Wallace model and NOAA-AVHRR NDVI data to feed a distributed hydrological model over the Mekong River basin. Journal of Hydrology, 327(1-2): 151-173.

Zhu G F, Su Y H, Li X, et al. 2013. Estimating actual evapotranspiration from an alpine grassland on Qinghai-Tibetan plateau using a two-source model and parameter uncertainty analysis by Bayesian approach. Journal of Hydrology, 476: 42-51.

Zhu G F, Su Y H, Li X, et al. 2014a. Modelling evapotranspiration in an alpine grassland ecosystem on Qinghai-Tibetan plateau. Hydrological Process, 28(3): 610-619.

Zhu G F, Lu L, Su Y H, et al. 2014b. Energy flux partitioning and evapotranspiration in a sub-alpine spruce forest ecosystem. Hydrological Processes, 28(19): 5093-5104. 